\title{
Bisphenol A migration from plastic materials: direct insight of ecotoxicity in Daphnia magna
}

\author{
Catarina Mansilha • Poliana Silva • Sónia Rocha • \\ Paula Gameiro • Valentina Domingues • Carina Pinho • \\ Isabel M. P. L. V. O. Ferreira
}

\begin{abstract}
Bisphenol A (BPA) is an endocrine disrupting chemical (EDC) whose migration from food packaging is recognized worldwide. However, the real overall food contamination and related consequences are yet largely unknown. Among humans, children's exposure to BPA has been emphasized because of the immaturity of their biological systems. The main aim of this study was to assess the reproductive impact of BPA leached from commercially available plastic containers used or related to child nutrition, performing ecotoxicological tests using the biomonitoring species Daphnia magna. Acute and
\end{abstract}

chronic tests, as well as single and multigenerational tests were done. Migration of BPA from several baby bottles and other plastic containers evaluated by GC-MS indicated that a broader range of foodstuff may be contaminated when packed in plastics. Ecotoxicological test results performed using defined concentrations of BPA were in agreement with literature, although a precocious maturity of daphnids was detected at $3.0 \mathrm{mg} / \mathrm{L}$. Curiously, an increased reproductive output (neonates per female) was observed when daphnids were bred in the polycarbonate (PC) containers $(145.1 \pm 4.3 \%$ to $264.7 \pm 3.8 \%)$, both in single as in multigenerational tests, in comparison with the negative control group $(100.3 \pm 1.6 \%)$. A strong correlated dose-dependent ecotoxicological effect was observed, providing evidence that BPA leached from plastic food packaging materials act as functional estrogen in vivo at very low concentrations. In contrast, neonate production by daphnids cultured in polypropylene and non-PC bottles was slightly but not significantly enhanced $(92.5 \pm 2.0 \%$ to $118.8 \pm 1.8 \%)$. Multigenerational tests also revealed magnification of the adverse effects, not only on fecundity but also on mortality, which represents a worrying trend for organisms that are chronically exposed to xenoestrogens for many generations. Two plausible explanations for the observed results could be given: a non-monotonic dose-response relationship or a mixture toxicity effect.

Keywords Endocrine disruptors · Bisphenol A · Food packaging $\cdot$ Low-dose effects $\cdot$ Mixture effects $\cdot$ Daphnids . Ecotoxicological tests

\section{Introduction}

Plastic materials are considered extremely convenient for food storage, preparation, and consumption. 
However, potential harmful substances can be leached from plastics and released into water and food matrices, especially at high temperatures (pasteurization, sterilization, or microwave heating; Erler and Novak 2010; Maia et al. 2009). This issue was focused recently by the European Union (EU; SEC 2011) and other international organizations (EFSA 2012; USFDA 2012) that have shown concern about the real overall food contamination and cumulative effects of such substances. Some of the leached compounds are recognized or suspected to be endocrine disrupting compounds (EDCs), like bisphenol A (BPA). BPA is a chemical component of epoxy resins used in protective coatings and linings for food and beverage cans and vats, and is also a component of polycarbonate (PC), a plastic used to produce food containers, beverage bottles, infant feeding (baby) bottles and tableware (plates and mugs; EFSA 2012; Nam et al. 2010; USFDA 2012; Viñas et al. 2010).

BPA has been associated with increased incidence of cardiovascular disease, diabetes, reproductive cancers, fertility problems and other endocrine-related endpoints, even at a very low-level exposure, which remains a major challenge for scientists and regulators (Canada Environment 2009; Cunha and Fernandes 2010; De Coensel et al. 2009; EC 2010; Ehrlich et al. 2011; Erler and Novak 2010; Kortenkamp et al. 2012; Meeker et al. 2010; Wagner and Oehlmann 2009; USEPA 2010). In January 2011, the European Commission adopted the Directive 2011/8/EU as regards the restriction of use of BPA in plastic infant feeding bottles (EC 2011). Nevertheless, there are still hundreds of products on the market commercialized without any surveillance. In February 2012, following further consideration of new scientific studies, the European Food Safety Authority (EFSA) decided to undertake a full re-evaluation of the human risks associated with exposure to BPA through food contact materials, focusing in particular on possible lowdose effects and on the exposure of vulnerable groups, particularly at sensitive life cycle stages, as infants and children, that appear to be exposed to BPA primarily through food packaging materials and feeding products (EFSA 2012).

As a consequence of severe restrictions on substances identified as endocrine disruptors imposed by some pieces of legislation (as for example: Regulation (EC) No. 1907/2006; Regulation (EC) No. 1107/2009 and Regulation (EU) No. 528/2012), significant efforts have also been made at international level to accurately identify and assess endocrine disruptors' hazards. The Conceptual Framework (CF) from the Organisation for Economic Cooperation and Development (OECD) for testing and assessment of EDCs was recently reviewed in the light of the scientific progress obtained in this area (OECD 2011). Presently, it comprises of an Integrated Testing Strategy with five levels of organization. Level 5 consists of wholeorganism assays that provide more comprehensive data on adverse effects on relevant endpoints over more extensive parts of the life cycle of an organism. Invertebrate life cycle tests were added, including the Daphnia 21-day reproduction test or TG211, that was recently reviewed (OECD 2012). Daphnia magna is used since 1980 as a biomonitoring species, being an approved test model due to their sensitivity towards pollutants (ASTM 2004; OECD 1984, 2004, 2012; USEPA 2002).

Despite the actual controversy about how to interpret results of the Daphnia tests for identification, risk assessment, and testing strategy of EDCs (Brennan et al. 2006; Oetken et al. 2004), D. magna seems to be a valuable model for evaluating endocrine disruptors' effects. In the Final Report of the State of the Art Assessment of Endocrine Disrupters (Kortenkamp et al. 2012), it is stated that assays utilizing invertebrates offer some advantages over vertebrate models, namely that there are fewer ethical considerations when using invertebrates, doses are easier to deliver precisely in aquatic animals, and their small size and inexpensive cultural requirements allow larger datasets to be collected. Although few have been explored so far, invertebrate models have much to offer both as a means for investigating EDC effects relevant to vertebrates and as ecotoxicological models for screening chemicals for potential endocrine disrupting properties.

Two major goals were established for this study. The first one was to test several plastic containers used to feed children, such as baby bottles, an infant feeding cup, and some disposable and microwave-reheatable containers, since it is a household practice to store and freeze homemade baby food, as soups and purees, in little plastic boxes. Migration experiments were done under defined time and temperature conditions, as it was intended to simulate routine applications (boiling, washing, and reuse), using a gas chromatography-mass spectrometry (GC-MS) method that was developed and validated according to international conventions to provide an accurate quantification of very low levels of BPA (Mansilha et al. 2010, 2012). The other goal of this study was to assess the impact of BPA on the crustacean $D$. magna performing preliminary acute and chronic tests according to $\operatorname{OECD}(2004,2012)$, and then investigating the impact of direct exposure on reproductive endpoints of daphnids bred in the plastic containers. These last experiments were similar to those of Martin Wagner and Jörg Oehlmann that provided the first evidence that substances leaching from plastic food packaging materials act as functional estrogens in vivo (Wagner and Oehlmann 2009). Transgenerational chronic effects were also observed. Multigenerational experimental designs were employed to account for continuous exposure to BPA and, eventually, to other plastic reaching materials, in order to assess the long-term chronic effects over several generations. 


\section{Material and methods}

Chemicals and reagents

Bisphenol A, 2,2'-bis(4-hydroxyphenyl)propane CAS Number 80-05-7, $\geq 99 \%$, deuterated-BPA CAS Number 96210-87-6 (BPA-d ${ }_{16}$ ), and 2,2,2-trifluoro- $N$-methyl- $N$ (trimethylsilyl)acetamide CAS Number 24589-78-4, $>98 \%$ (MSTFA) were supplied by Sigma-Aldrich (Steinheim, Germany). Acetic acid (glacial) $100 \%$ was supplied by Merck (Darmstadt, Germany). Methanol and ethyl acetate were of organic trace analysis grade (SupraSolv) and were also supplied by Merck. Strata SDB-L $(200 \mathrm{mg}, 3 \mathrm{~mL})$ cartridges were from Phenomenex (Torrance, CA, USA). Ultra-pure water $(0.054 \mu \mathrm{S} / \mathrm{cm})$ was obtained by using a Milli-Q system from Millipore (Milford, MA, USA).

ASTM synthetic hard water (ASTM 2008) was used as culture medium for D. magna. The rearing procedures followed the recommendations of standard protocols (OECD 2004, 2012). Individual trace elements, macronutrients, and vitamins (thiamine, cyanocobalamine, and biotine) were from Merck.

Daphnids were fed with a concentrated suspension of the green algae Pseudokirchneriella subcapitata. The algae and the marine seaweed extract were supplied by Glenside Organics Ltd (UK). Woods Hole MBL growth medium supplied all macro- and micronutrients for the green algae P. subcapitata. The macronutrients used on MBL culture medium were calcium chloride dihydrate $\left(\mathrm{CaCl}_{2} \cdot 2 \mathrm{H}_{2} \mathrm{O}\right)$, magnesium sulfate heptahydrate $\left(\mathrm{MgSO}_{4} \cdot 7 \mathrm{H}_{2} \mathrm{O}\right)$, sodium bicarbonate $\left(\mathrm{NaHCO}_{3}\right)$, dipotassium phosphate $\left(\mathrm{K}_{2} \mathrm{HPO}_{4}\right)$, sodium nitrate $\left(\mathrm{NaNO}_{3}\right)$, and sodium metasilicate pentahydrate $\left(\mathrm{NaSiO}_{3} \cdot 9 \mathrm{H}_{2} \mathrm{O}\right)$ from Prolabo (Belgium). The micronutrients ferric chloride hexahydrate $\left(\mathrm{FeCl}_{3} \cdot 6 \mathrm{H}_{2} 0\right)$, copper (II) sulfate pentahydrate $\left(\mathrm{CuSO}_{4} \cdot 5 \mathrm{H}_{2} \mathrm{O}\right)$, zinc sulfate heptahydrate $\left(\mathrm{ZnSO}_{4} \cdot 7 \mathrm{H}_{2} \mathrm{O}\right)$, cobalt chloride hexahydrate $\left(\mathrm{CoCl}_{2} \cdot 6 \mathrm{H}_{2} \mathrm{O}\right)$, manganese chloride tetrahydrate $\left(\mathrm{MnCl}_{2} \cdot 4 \mathrm{H}_{2} \mathrm{O}\right)$, sodium molybdate dihydrate $\left(\mathrm{NaMoO}_{4} \cdot 2 \mathrm{H}_{2} \mathrm{O}\right)$, and tris(hydroxymethyl)aminomethane were also from Prolabo.

\section{Migration studies}

\section{Analytical procedure and method validation}

BPA extraction was performed by solid phase extraction (SPE) using Strata SDB-L cartridges. After elution, the extracts were evaporated to dryness, reconstituted within ethyl acetate, and derivatized using MSTFA (Mansilha et al. 2012; Viñas et al. 2010).

Six BPA matrix-standard calibration solutions, at concentration levels ranging from 0.075 to $0.750 \mu \mathrm{g} / \mathrm{L}$, were prepared just before the extraction procedure.
BPA- $\mathrm{d}_{16}$, at a concentration of $0.750 \mu \mathrm{g} / \mathrm{L}$, was used as procedural or instrumental internal standard for assessing the effectiveness of the extraction technique and monitoring the recovery during sample analysis due to a more or less complex sample preparation. Chromatographic analyses were carried out in a Shimadzu GCMS-QP2010 Gas Chromatograph Mass Spectrometer equipped with a fused-silica capillary column coated with $5 \%$ diphenylmethylsiloxane, VF-5 MS (30 $\mathrm{m} \times 0.25 \mathrm{~mm}$ I.D., $0.25 \mu \mathrm{m}$ film thickness) from Varian. Injections $(1 \mu \mathrm{L})$ were made in the splitless mode with a 1.0-min purge-off time and injector temperature set at $275{ }^{\circ} \mathrm{C}$. Calibration standards and water samples were analyzed using the following oven temperature program: initial temperature $60{ }^{\circ} \mathrm{C}$ (held for $2 \mathrm{~min}$ ), increased by $10{ }^{\circ} \mathrm{C} / \mathrm{min}$ to $200{ }^{\circ} \mathrm{C}$ (held for $1 \mathrm{~min}$ ), increased again by $10{ }^{\circ} \mathrm{C} / \mathrm{min}$ to $275^{\circ} \mathrm{C}$, and held at this temperature for $10 \mathrm{~min}$. GC was directly interfaced to a Shimadzu QP 2010 quadrupole mass spectrometer with an interface temperature of $250{ }^{\circ} \mathrm{C}$ and ionization by $70 \mathrm{eV}$ electron impact. The transfer line was set at $275{ }^{\circ} \mathrm{C}$ and the source at $200{ }^{\circ} \mathrm{C}$ (Mansilha et al. 2012).

Positive fragment ions $(\mathrm{m} / \mathrm{z}$ ion mass/charge ratio) were analyzed over $43-500 \mathrm{~m} / \mathrm{z}$ mass range in full scan mode and in selected-ion monitoring (SIM) mode.

The identification of BPA in the samples was done according the following conditions: (a) the relative or the absolute retention time of the sample component matched that of the authentic compound within a limit deviation of $\pm 0.02 \mathrm{~min}$; (b) the selected diagnostic ions were present at the substance specific retention time; (c) the relative intensities of two of the chosen diagnostic ions measured in the sample do not deviate by more than $25 \%$ (Stottmeister et al. 2009); and comparison with comprehensive mass-spectral libraries (such as NIST) that allowed an unequivocal identification of target compound.

The ions selected for quantification and identification purposes were mass-to-charge ratio $(\mathrm{m} / \mathrm{z})$ : 386 (molecular ion,

$\left.[\mathrm{M}]^{\bullet}\right), 369,368$, and 217 for BPA-d $d_{16}$ and $372[\mathrm{M}]^{\bullet}, 357$, and 217 for BPA with relative intensities of $I_{1} 372(100 \%), I_{2} 357$ (25\%), and $I_{3} 217$ (5\%).

Validation was done mainly according to the International Conference on Harmonization recommendations (ICH 2005), as well as to some European and American validation guidelines (EURACHEM 1998; NCCLS 2002; NCCLS 2004; SANCO 2009; USFDA 2001) with specifications for endocrine disrupting analysis and/or GC-MS methodology.

As the assumption of homoscedasticity was not met for analytical data, a weighted least squares linear 
regression procedure was applied as a simple and effective way to counteract the greater influence of the higher concentrations on the fitted regression analysis, improving accuracy at the lower end of the calibration curve (Miller and Miller 2005).

Several parameters such as: specificity and selectivity, linearity and linear range, limits of detection and quantification, precision, accuracy, trueness (recovery), stability, and robustness were determined and accessed.

\section{Sampling plan}

Twelve different brands of baby bottles of reusable PC, nonPC, and PP (polypropylene, commonly labeled "non-BPA" or "BPA-free"), an infant feeding cup, and three plastic containers used for food storage, two of PP and one of PC, were purchased in Oporto retail stores and used for hightemperature testing. Containers were filled with ultra-pure water and heated to $100{ }^{\circ} \mathrm{C}$ in a microwave. The boiling temperature was maintained for $1 \mathrm{~min}$. Then the samples were left at room temperature for $2 \mathrm{~h}$ and, finally, were preconcentrated using SPE. High-temperature test was used because boiling the water in the microwave directly in baby bottles for sterilization purposes is a usual procedure when preparing formula. Also, the distribution of small amounts of hot soups and meals in small containers, which are then kept in the freezer for daily use, is frequent nowadays.

As baby bottles are typically used with their contents kept near body temperature, migration tests were also carried out at $40{ }^{\circ} \mathrm{C}$ for $240 \mathrm{~h}$ (USFDA 2007). This 10-day testing period was included in order to mimic repetitive use of baby bottles.

All containers were cleaned before use in a domestic dishwasher $\left(55^{\circ} \mathrm{C}\right)$ with exception of BB-7 (similar to BB-8) that was manually cleaned according to manufacturer's instructions to test dishwashing impact on BPA migration. Experimental planning is summarized in Table 1.

\section{Biological tests}

D. magna were obtained from continuous cultures maintained in the laboratory in ASTM hard water at a temperature of $20^{\circ} \mathrm{C} \pm 1{ }^{\circ} \mathrm{C}$ and a 16-h light:8-h dark photoperiod, at a light intensity of 100-1,000 Lx. Animal density was 15 individuals per 1,000 mL and medium was renewed three times a week. Daphnids were fed with algae (Pseudokirchneriella subcapitata) with a density of $5 \times 10^{5}$ cells $/ \mathrm{mL}$ and an organic additive (Baird et al. 1989). Physical-chemical parameters as total hardness, oxygen concentration, $\mathrm{pH}$, temperature, conductivity, and total organic carbon (TOC) were measured at least once a week, in fresh and old ASTM media, in the control(s) and in the test vessels.

\section{Preliminary studies}

Daphnids were subjected to a reference chemical test with potassium dichromate to ensure the validity of the experiments (ISO 2010). After that, acute tests were performed according to OECD 202 protocol (OECD 2004) as range finding tests. Young daphnids, aged less than $24 \mathrm{~h}$ at the start of the test, were placed in glass test vessels and exposed to BPA for a period of $48 \mathrm{~h}$. Tests were conducted in glass vessels using nine concentrations of BPA (1.0, 5.0, 7.0, 9.0, 10.0, 11.0, 13.0, 15.0, and $20.0 \mathrm{mg} / \mathrm{L})$ and untreated controls. Ten replicates per test concentration level and control were prepared. Immobilization (after $15 \mathrm{~s}$ of gentle agitation) was recorded at 24 and $48 \mathrm{~h}$ and was compared with the controls. The results were analyzed in order to calculate the $\mathrm{EC}_{50}$ at $48 \mathrm{~h}$ (concentration estimated to immobilize $50 \%$ of the daphnids within a stated exposure period) as well as the lowest-observed effect concentration value (LOEC) and the no-observed-effect concentration value (NOEC).

The reproduction test was done according to the OECD 211 protocol (OECD 2012), whose primary objective is to assess the effect of chemicals on the reproductive output of D. magna and, to this end, young female Daphnia (the parent animals), aged less than $24 \mathrm{~h}$ at the start of the test, are exposed to the test substance added to water at a range of concentrations during 21 days. This long-term toxicity test allowed the examination of the survival of the parent animals, molting frequency, and the number of newborns produced. Three BPA concentrations were tested (one third of $\mathrm{EC}_{50}$ and two other concentrations above and below $\mathrm{EC}_{50} / 3$ ), using also ten replicates (females of D. magna) per concentration and control.

Multigenerational tests were also performed. Normally developed neonates (maximum age $24 \mathrm{~h}$ at the start of the test originated from the latest brood of daphnids from the reproduction test), which were exposed towards selected test concentrations during their embryonic development in mater, were further exposed to the same substance concentration. Neonates from unexposed control organisms were treated the same way and held in uncontaminated medium. Ten replicates were used for each BPA concentration and control.

\section{Exposure tests. Breeding of D. magna in the plastic containers}

After standardization of the methodologies, reproduction tests were carried in the plastic containers. In order to assess the biological impact of the BPA in real exposure conditions, individuals of D. magna were inserted and bred in several baby bottles and in other plastic containers. Two reproductive methodologies were applied using single and multigenerational tests. 
Table 1 Containers used in the study and applied tests

\begin{tabular}{|c|c|c|c|c|}
\hline Container brand & Vol (L) & Recycling symbol & Migration tests & Cost \\
\hline \multicolumn{5}{|l|}{ Baby bottle } \\
\hline BB-1 & 0.15 & $7: \mathrm{PC}$ & High temperature $\left(100^{\circ} \mathrm{C}, 24 \mathrm{~h}\right)$; Repeated use $\left(40^{\circ} \mathrm{C} ; 240 \mathrm{~h}\right)$ & Cheap \\
\hline BB-2 & 0.15 & 7:PC & High temperature $\left(100^{\circ} \mathrm{C}, 24 \mathrm{~h}\right)$; Repeated use $\left(40^{\circ} \mathrm{C} ; 240 \mathrm{~h}\right)$ & Cheap \\
\hline BB-3 & 0.15 & $7: \mathrm{PC}$ & High temperature $\left(100^{\circ} \mathrm{C}, 24 \mathrm{~h}\right)$; Repeated use $\left(40^{\circ} \mathrm{C} ; 240 \mathrm{~h}\right)$ & Expensive \\
\hline BB-4 & 0.40 & $7: \mathrm{PC}$ & High temperature $\left(100^{\circ} \mathrm{C}, 24 \mathrm{~h}\right)$; Repeated use $\left(40^{\circ} \mathrm{C} ; 240 \mathrm{~h}\right)$ & Expensive \\
\hline BB-5 & 0.30 & 7:PC & High temperature $\left(100^{\circ} \mathrm{C}, 24 \mathrm{~h}\right)$ & Expensive \\
\hline BB-6 & 0.20 & 7:PC & High temperature $\left(100^{\circ} \mathrm{C}, 24 \mathrm{~h}\right)$; Repeated use $\left(40^{\circ} \mathrm{C} ; 240 \mathrm{~h}\right)$ & Expensive \\
\hline BB-7 & 0.15 & Non-PC & High temperature $\left(100^{\circ} \mathrm{C}, 24 \mathrm{~h}\right)$ & Cheap \\
\hline BB-8 & 0.15 & Non-PC & High temperature $\left(100^{\circ} \mathrm{C}, 24 \mathrm{~h}\right)$ & Cheap \\
\hline BB-9 & 0.25 & Non-PC & High temperature $\left(100^{\circ} \mathrm{C}, 24 \mathrm{~h}\right)$; Repeated use $\left(40^{\circ} \mathrm{C} ; 240 \mathrm{~h}\right)$ & Cheap \\
\hline BB-10 & 0.25 & 5:PP (BPA free) & High temperature $\left(100^{\circ} \mathrm{C}, 24 \mathrm{~h}\right)$ & Expensive \\
\hline BB-11 & 0.25 & 5:PP (BPA free) & High temperature $\left(100^{\circ} \mathrm{C}, 24 \mathrm{~h}\right)$ & Expensive \\
\hline BB-12 & 0.26 & 5:PP (BPA free) & High temperature $\left(100^{\circ} \mathrm{C}, 24 \mathrm{~h}\right)$ & Expensive \\
\hline \multicolumn{5}{|c|}{ Infant feeding cup } \\
\hline Cup-1 & 0.15 & Non-PC & High temperature $\left(100^{\circ} \mathrm{C}, 24 \mathrm{~h}\right)$ & Cheap \\
\hline \multicolumn{5}{|c|}{ Household plastic container } \\
\hline $\mathrm{C}-2$ & 0.50 & 5:PP & High temperature $\left(100^{\circ} \mathrm{C}, 24 \mathrm{~h}\right)$ & Cheap \\
\hline $\mathrm{C}-3$ & 0.25 & 5:PP & High temperature $\left(100{ }^{\circ} \mathrm{C}, 24 \mathrm{~h}\right)$ & Cheap \\
\hline $\mathrm{C}-4$ & 0.50 & $7: \mathrm{PC}$ & High temperature $\left(100^{\circ} \mathrm{C}, 24 \mathrm{~h}\right)$ & Expensive \\
\hline
\end{tabular}

Single generation reproduction test The single generation test was performed in ten baby bottles (BB-1, BB-2, BB-4, BB-9, BB-10, and five identical BB-8 ${ }_{(a \text { to } e)}$, used to monitor the reproducibility of the test), in the infant feeding cup and in the three household plastic containers. The ASTM culture medium was previously boiled at $100{ }^{\circ} \mathrm{C}$, placed in each container and cooled to room temperature $\left(18-22{ }^{\circ} \mathrm{C}\right)$. One D. magna, age under $24 \mathrm{~h}$, was placed in each plastic test vessel. Tests were performed as described in OECD 211 guideline. During the test period, the frequency of female reproduction, survival, and the number of neonates were evaluated. The results were compared with those of the control glass beakers $(n=6)$.

Multigenerational tests To verify the impact of BPA, and eventually of other plastic leached compounds, in several generations of $D$. magna, two reproduction tests were performed. First, five daphnids in different life stages (N0, N1, N2, N3, N4) were placed simultaneously in each test container (BB-2, BB-4, BB-9, BB-10, Cup-1, C-4) during 21 days. The frequency of female reproduction, survival, and the number of neonates was recorded.

Secondly, another toxicity study was performed over six generations during several months to evaluate the effects of long-term exposure of the daphnids. In this case, newly hatched neonates (F0) of the third brood from age-synchronized mothers were selected randomly and transferred individually into each tested container
(BB-1, BB-2, BB-4, BB-8, BB-10, and C-3). Simultaneously, four neonates were also transferred to glass vials and used as control. All newly hatched neonates from each female were removed and counted, and after 21 days, females of the F0 generation were also removed and a single neonate per clutch was randomly selected as the F1 generation to continue the experiment in the plastic or glass container. Daphnids of subsequent generations were treated as in the F0 generation. Dead animals were not replaced. The experiment was finished after the neonates (F6) of the generation F5 had been hatched.

These studies were important to evaluate not only one generation of newborns but also the behavior of further generations, similarly to what happens in the environment. All multigenerational studies were performed in the same conditions described for single tests.

\section{Data analysis}

The effective concentration $\left(\mathrm{EC}_{50}\right.$ value) for the parameter immobilization was calculated using the results obtained in the $48 \mathrm{~h}$ acute toxicity tests. The dose-response curve was fitted via the probit model.

Data differences were tested for significance by means of one-way analysis of variance (ANOVA). When differences among groups were significant, the Dunnett's test was employed to compare the control group with each of 
the experimental groups for calculation of NOEC and LOEC. Statistical significance was set at $p<0.05$, where the null hypothesis claims that there is no difference between samples and control growth rate. One-sample independent $t$ tests and two-sided $t$ tests, with a significance level of 0.05 , were also carried out.

\section{Results and discussion}

Analytical method validation

Specificity and selectivity were evaluated by comparing the chromatograms of matrix-blank samples (samples of ultrapure water) with an aqueous solution of the silylated analyte at a concentration near the limit of quantification. No significant interference has been detected at the retention time of BPA. Selectivity was also assessed by the comparison of the analyte mass spectrum with a library spectrum.

Calibration in SIM mode was performed using external standardization. Matrix-calibration standards were prepared under the same conditions applied to samples and injected in triplicate. Regression parameters obtained after application of the weighting factors were calculated and are presented in Table 2. The random errors in the $y$ direction $\left(\mathrm{S}_{y / x}\right)$, as well as the standard deviations for the slope $\left(\mathrm{S}_{b}\right)$ and intercept $\left(\mathrm{S}_{a}\right)$, were used to estimate confidence limits given by: $b \pm$ $t_{(n-2)} \mathrm{S}_{b}$ and $a \pm t_{(} t_{n-2)} \mathrm{S}_{a}$, where the $t$ value is taken at $95 \%$ confidence level and (n-2) degrees of freedom. The percentages of $\mathrm{S}_{(b) w / b}$ satisfy the validation condition of the calibration curve with a value less than $5 \%$ ( Miller and Miller 2005).

Good sensitivity (LOD $7.76 \mathrm{ng} / \mathrm{L}$ ) was found under the optimized experimental conditions and the uncertainty for the calibration curve $(U)$ that reflects the variability of the method was calculated according to: $U=\mathrm{S} x_{0 w} / x_{0}$.

Intraday and interday precision results were in accordance with ICH, USFDA, and NCCLS requirements (ICH 1994, 1995; NCCLS 2002; USFDA 2001). Results were within $15 \%$ (RSD), except at the LOQ, which assume a value of $\pm 20 \%$. Accuracy was expressed as absolute bias and was inferior to $\pm 15 \%$ of the accepted true value (ICH 1995).

Instrumental precision was evaluated and presented an acceptable value. Media and amplitude control charts of BPA- $d_{16}$, used for process evaluation through recovery studies, showed no relevant tendency, so no procedural review was necessary (Mansilha et al. 2012).

Migration of bisphenol A from plastic containers

Table 3 summarizes the results of the high temperature migration tests showing, unequivocally, that BPA migration from PC containers is higher when compared to other plastic materials. This is in agreement with other studies that documented that BPA migration increase at higher temperatures due, probably, to the hydrolysis of the PC polymer or to the liberation of non-reactive monomers (Kubwabo et al. 2009).

Results have also shown that there is no relationship between BPA concentrations and the price of the product, but only with the polymers they are made of. BB10, BB-11, and BB-12, labeled as BPA Free, as well as $\mathrm{C}-2$ and $\mathrm{C}-3$, showed only residual levels of BPA. This confirms that 5:PP containers may be considered an appropriate alternative to the $\mathrm{PC}$ ones in order to minimize BPA exposure.

The impact of dishwashing on BPA migration was also investigated. Two identical baby bottles were tested simultaneously for two different wash procedures. BPA concentration in the sample collected from the bottle washed in the dishwasher (BB-8) was $0.34 \mu \mathrm{g} / \mathrm{L}$; while in the manual cleaned bottle (BB-7), a significantly lower value of $0.06 \mu \mathrm{g} / \mathrm{L}$ was obtained $(p<0.05)$.

The 10-day test was designed to simulate repeated use and to investigate the highest concentration levels that could potentially migrate from the materials used to fabricate reusable baby bottles at a temperature near body temperature. Six brands of baby bottles (BB-1, BB-2, BB-3, BB-4, BB-6, and BB-9) were filled with water and incubated for $240 \mathrm{~h}$ (10 days) at $40^{\circ} \mathrm{C}$. BB-5, as well as BB-7 and BB-8, were not tested as their high temperature test results were similar to BB-3 and to BB-9, respectively. The "BPA free" baby bottles (BB-10, BB-11, and BB-12) were also not processed as they revealed no significant BPA levels. Residual BPA ranged from 1.83 to $5.63 \mu \mathrm{g} / \mathrm{L}$ with an average of $3.75 \mu \mathrm{g} / \mathrm{L}$. Comparing these results with those obtained for the same six baby bottles in the high-temperature migration test, an average BPA concentration value of $6.13 \mu \mathrm{g} / \mathrm{L}$ was achieved. So, BPA seems to be more readily released (1.6 times) at higher temperatures.

Table 2 Method validation data

\begin{tabular}{|c|c|c|c|c|c|c|c|c|c|}
\hline & $\begin{array}{l}b_{\mathrm{w}} \pm t_{(n-2)} \\
S_{(b) \mathrm{w}}(95 \%)\end{array}$ & $\begin{array}{l}a_{\mathrm{w}} \pm t_{(n-2)} \\
S_{(a) w}(95 \%)\end{array}$ & $S_{(y / x) \mathrm{w}}$ & $S_{(b) \mathrm{w}} / b_{\mathrm{w}}(\%)$ & $r_{\mathrm{w}}$ & $\begin{array}{l}\text { LOD } \\
(\mathrm{ng} / \mathrm{L})\end{array}$ & $\begin{array}{l}\text { LOQ } \\
(\mathrm{ng} / \mathrm{L})\end{array}$ & $U_{0.075 \mathrm{ppb}}(\%)$ & $U_{0.750 \mathrm{ppb}}(\%)$ \\
\hline Bisphenol A & $1,500.41 \pm 19.41$ & $-803.23 \pm 5,808.37$ & $2,588.30$ & 0.47 & 0.9998 & 7.76 & 25.88 & 3.97 & 1.13 \\
\hline
\end{tabular}

Calibration parameters and related uncertainties 
Table 3 Results of BPA levels obtained for plastic containers tested at high temperature

\begin{tabular}{lll}
\hline Container brand & Recycling symbol & BPA concentration $(\mu \mathrm{g} / \mathrm{L})$ \\
\hline Baby bottle & & \\
BB-1 & $7: P C$ & 3.99 \\
BB-2 & $7: P C$ & 10.3 \\
BB-3 & $7: P C$ & 1.45 \\
BB-4 & 7:PC & 15.2 \\
BB-5 & 7:PC & 1.02 \\
BB-6 & 7:PC & 5.54 \\
BB-7 & Non-PC & 0.06 \\
BB-8 & Non-PC & 0.34 \\
BB-9 & Non-PC & 0.28 \\
BB-10 & 5:PP (BPA free) & 0.04 \\
BB-11 & 5:PP (BPA free) & $<$ LOQ \\
BB-12 & 5:PP (BPA free) & 0.05 \\
Infant feeding cup & & \\
Cup-1 & Non-PC & 0.08 \\
Household plastic container & \\
C-2 & 5:PP & 0.04 \\
C-3 & 5:PP & 0.05 \\
C-4 & 7:PC & 0.26 \\
\hline
\end{tabular}

\section{Biological tests}

Physical-chemical parameters of the ASTM hard water were measured during the tests. The following values were obtained: total hardness $201 \pm 5 \mathrm{mg} / \mathrm{LCaCO}_{3}$, oxygen concentration $9.6 \pm 0.8 \mathrm{mg} / \mathrm{LO}_{2}, \mathrm{pH}$ range $7.0-8.0, \mathrm{TOC}<2 \mathrm{mg} / \mathrm{L}$, and conductivity $480 \pm 15 \mu \mathrm{Scm}^{-1}$.

\section{Preliminary studies}

The value of $\mathrm{EC}_{50}$ obtained in $24 \mathrm{~h}$ for cultures of $D$. magna exposed to potassium dichromate was $1,400 \mu \mathrm{g} / \mathrm{L}$ $( \pm 50 \mu \mathrm{g} / \mathrm{L})$, which is within the range stipulated by ISO $6341\left(\mathrm{EC}_{50} 600\right.$ to $\left.1,700 \mu \mathrm{g} / \mathrm{L}\right)$. The acute toxicity test result, expressed as $\mathrm{EC}_{50}$, was $9940 \mu \mathrm{g} / \mathrm{L}( \pm 130 \mu \mathrm{g} / \mathrm{L})$ after $48 \mathrm{~h}$ of exposure. This value was in agreement with those reported by other authors (1,000 to $20,000 \mu \mathrm{g} / \mathrm{L}$; Alexander et al. 1988; Brennan et al. 2006; Caspers 1998; Mu et al. 2005; Staples et al. 1998), confirming that the stipulated laboratory conditions were successfully applied. Based also on the acute test data, the LOEC was determined to be $5,000 \mu \mathrm{g} / \mathrm{L}$ resulting in an NOEC of $3,000 \mu \mathrm{g} / \mathrm{L}$. These results were in accordance with those reported on the European Union Risk Assessment Report published on 2003 (EU 2003).

The reproduction toxicity test was processed during 21 days for three different concentrations of BPA $(1,000$, $3,000$, and 5,000 $\mu \mathrm{g} / \mathrm{L})$ plus control. BPA concentrations were determined weekly and were satisfactorily maintained within $\pm 20 \%$ of the nominal concentration. Neonates from each replicate were counted and removed from the test vessels daily after the appearance of the first brood.

No adult mortality occurred in the control vessels over the 21-day testing period. The mean number of live offspring produced per control parent animal was 61 and the minimum number was 60 ; thus, this test was valid according to the OECD guideline 211 biological criterions.

Daphnids in BPA concentration of $5,000 \mu \mathrm{g} / \mathrm{L}$ died after 14 days. In 1,000 and 3,000 $\mu \mathrm{g} / \mathrm{L}$, results demonstrated that after the 21-day trial the number of newborns per live adult obtained in control and in BPA tests underwent no significant differences $(p \leq 0.05)$. These results were consistent with the acute test results and with the study of Staples et al. (1998), in which a concentration of $3150 \mu \mathrm{g} / \mathrm{L}$ of BPA promoted no relevant effects. However, it should be noted that it was observed a precocious maturity in the concentration of $3,000 \mu \mathrm{g} / \mathrm{L}$ of BPA when compared to control (Fig. 1). Caspers also found an accelerating effect of BPA on offspring production (Caspers 1998).

So, in this study, no statistically significant differences were observed, at a significance level of $\alpha=0.05$, between the total live offspring per survival female of the control batch and the two BPA batches $(1,000$ and 3,000 $\mu \mathrm{g} / \mathrm{L})$. However, at 3,000 $\mathrm{g} / \mathrm{L}$, an early enhancement was observed between days 6 and 13 .

Multigenerational tests were also performed for the same concentrations of BPA. The exposure conditions and the applied procedures were similar to those of the reproduction toxicity test.

Overall fecundity (mean neonates per female over 21 days) was not affected in F0 (1st brood) at 1,000 and 3,000 $\mu \mathrm{g} / \mathrm{L}$ treatment levels; but in F1 (2nd brood) and F2 (3th brood), fecundity was significantly affected by BPA $(p<0.05)$ and a precocious maturity was also recorded. In F3 (4th brood), an enhancement was observed in $1,000 \mu \mathrm{g} / \mathrm{L}$, although in 3,000 $\mu \mathrm{g} / \mathrm{L}$ daphnids died after 16 days. F4 daphnids (5th brood) died on the 8 th day in $1,000 \mu \mathrm{g} / \mathrm{L} \mathrm{BPA}$ test (Fig. 2).

Molting behavior and survival are toxicological endpoints which have been shown to be adversely affected by this endocrine disrupting chemical. Data analysis demonstrates the effects of BPA on the survival and reproduction over generations, providing insight into the relative sensitivity and higher biological level consequences of BPA exposure.

Exposure tests. Breeding of D. magna in the plastic containers

Single generation chronic test Single generation reproduction toxicity test was performed during 21 days in 10 baby bottles, in the feeding cup, and in some household plastic 
Fig. 1 Mean cumulative number of neonates produced by Daphnia magna exposed to various BPA concentrations and control over the time course of the experiment $(n=10)$

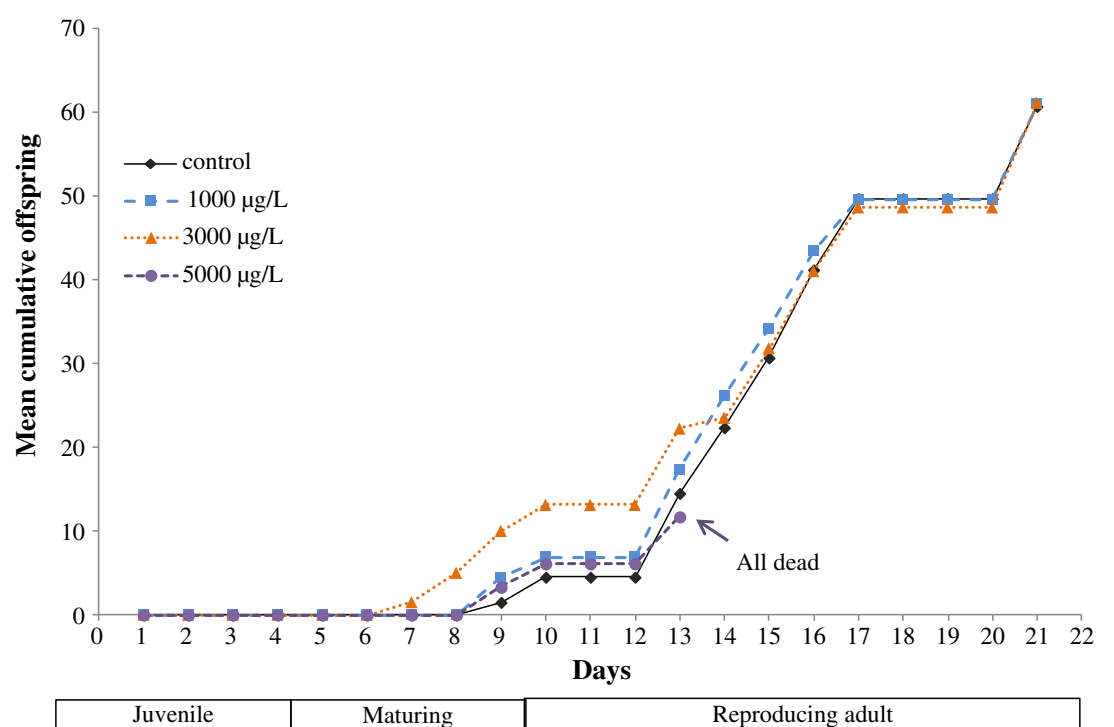

containers. Six glass beakers were used as negative control and a confidence interval $(\mathrm{CI})$ of \pm 1.9 was calculated with a level of significance of 0.05 . A one-tailed $t$ test was then applied in order to check if the D. magna offspring in plastic containers was significantly different from the control. A significantly higher offspring number was observed in all samples, except in Cup-1, C-2, and C-3, when compared with control. The results achieved with the five baby bottles BB- 8 shown the reproducibility of the test (Fig. 3), with offspring numbers between 83 and 86 and a confidence level of $\pm 1.4(\alpha=0.05)$. Data analysis also demonstrated a positive correlation between BPA concentrations obtained in the high temperature test $\left(100^{\circ} \mathrm{C}\right)$ and the offspring numbers $\left(r^{2}=0.97\right)$.

Multigenerational chronic tests As daphnids undergo distinct life stages during their development, which may be affected differently by toxicant pulses, a first multigenerational test was performed in six of the plastic containers used in single test (BB-2, BB-4, BB-9, BB-10, Cup-1, C-4). There were used immature juveniles ( $0-5$ days old - N0 and N1), organisms approaching sexual maturity (5-10 days old - N2 and N3) and reproducing adults (10-15 days oldN4) in each studied container. Data are also showed in Fig. 3. Three glass beakers were used as control and a CI of \pm 2.0 was calculated with a level of significance of 0.05 . A one-tailed $t$ test was performed. It was observed a significant higher offspring in BB-2 and BB-4, which were PC baby bottles, as expected regarding single test results. There was also a positive correlation between BPA concentration and the offspring numbers $\left(r^{2}=0.83\right)$.

These experiments demonstrated that BPA seems to disrupt the reproductive process, both in single and in
Fig. 2 Multigenerational chronic test. Effects of BPA on brood sizes over five generations of D. magna

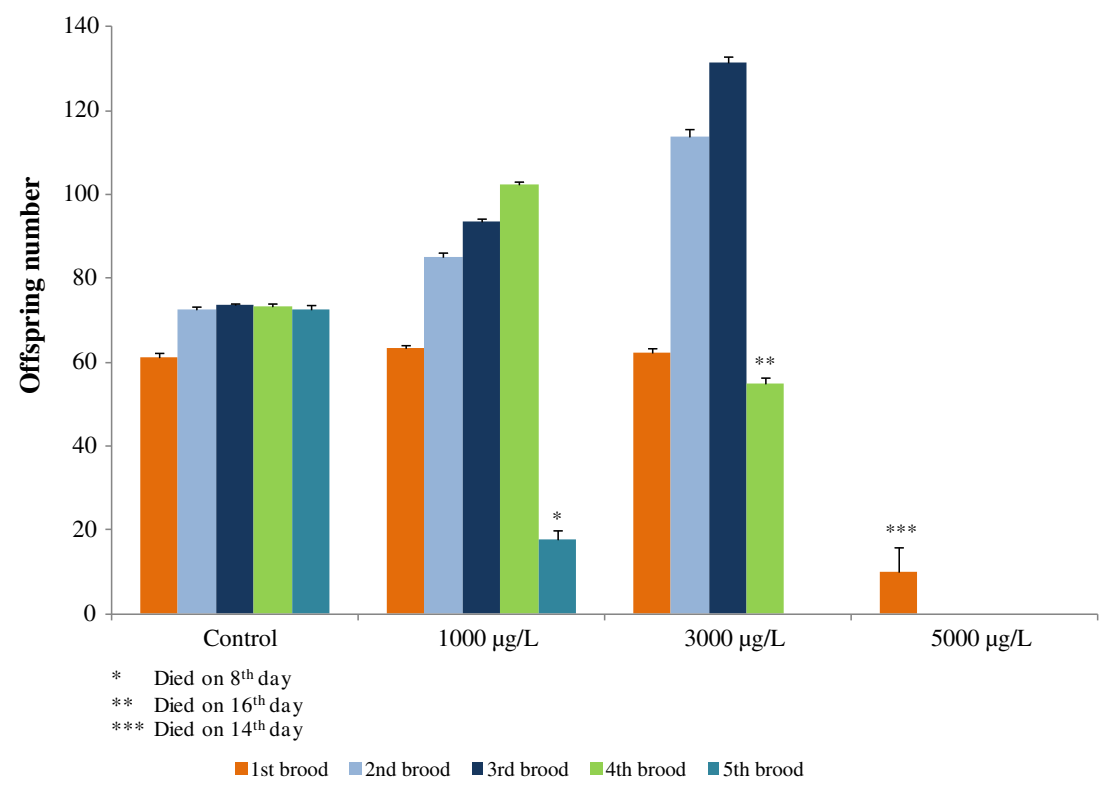


Fig. 3 Correlation between BPA migration results and single and multigenerational offspring numbers in the 21-day test

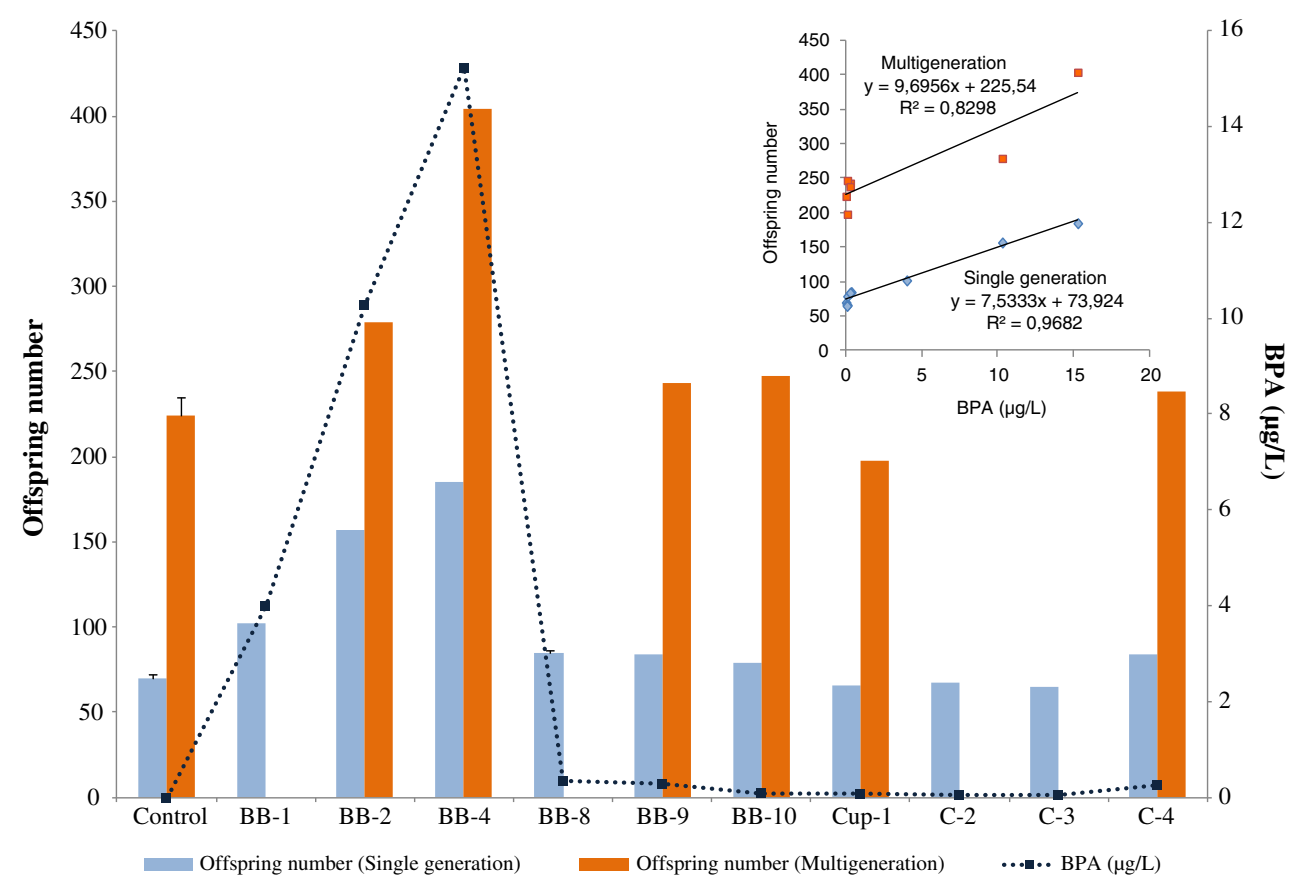

multigenerational tests, resulting in the production of more neonates when compared with controls. However, this conclusion contrasts with the previous studies with defined BPA concentrations (Fig. 1) that showed no significant impact of BPA at $3,000 \mu \mathrm{g} / \mathrm{L}$.

A second multigenerational study, performed over six generations, showed also a significant reproduction enhancement, especially in BB-2 and in BB-4, but also in BB-1 and BB-8, when compared with control.

As in single generation test, there were used five identical baby bottles BB-8 to assess the reproducibility, or the uncertainty, associated with the experiment and results showed no significant differences regarding offspring numbers for all generations, with confidence levels varying from 0.6 to 2.2, except for F5 were offspring numbers varied from 44 to 69 (confidence level 14.4).

In this study, it was observed that offspring numbers were almost constant over all generations for each baby bottle until F4 (5th brood). F5 daphnids (6th brood) died in BB-1, BB-2, and BB-4, demonstrating the effects of the exposure on parental mortality. As expected, in C-3 the results did not differ from control (Fig. 4). Daphnids exposed to higher BPA concentrations also matured faster than control animals in all generations.

It seems that breeding the crustacean D. magna in the plastic containers resulted in an increased reproductive output of daphnids and in the decrease of parental survival after five generations, especially for those cultured in PC bottles where higher concentrations of BPA were detected. Although these concentrations were far below than those used in defined concentrations testes, we can conclude that direct exposure to plastics produced evident ecotoxicological effects. These results could indicate a non-monotonic dose-response relationship, which is the basis of the "low dose" concept. The pharmacokinetics of low doses of bisphenol A has been discussed in the last years and there are already several studies on this subject. However, important knowledge data gaps have remained largely unaddressed. So, in connection with the efforts to characterize the risks associated with EDCs, it has been argued that the current risk assessment paradigm needs modification or has become obsolete because EDCs elicit effects at doses much lower than normally used in regulatory testing (Kortenkamp et al. 2012). Another plausible explanation for the observed results could be the existence of a mixture of leached substances in solution, since it is known that along with BPA, plastics release other compounds such as phthalates that are also considered endocrine disruptors (GonzálezCastro et al. 2011; Guart et al. 2011; National Research Council 2008). Although it is recognized that organisms face multifarious mixtures of environmental stressors rather than individual chemicals at set doses and that the effects of a mixture can be very different from the sum of the contributions of the individual compounds, until now little attention has been paid to the simultaneously interaction of different pollutants and to cumulative risks, firstly highlighted in the Framework for Cumulative Risk Assessment of USEPA (2003). This led to the concern that testing of single chemicals may completely underestimate effects in mixtures, leading to the erroneous conclusion that no effects are observed, whereas in fact, effects would be expected in the field environment where animals 
Fig. 4 Correlation between BPA migration results and the offspring numbers of Daphnia magna bred in different plastic containers and in control vessels over six generations

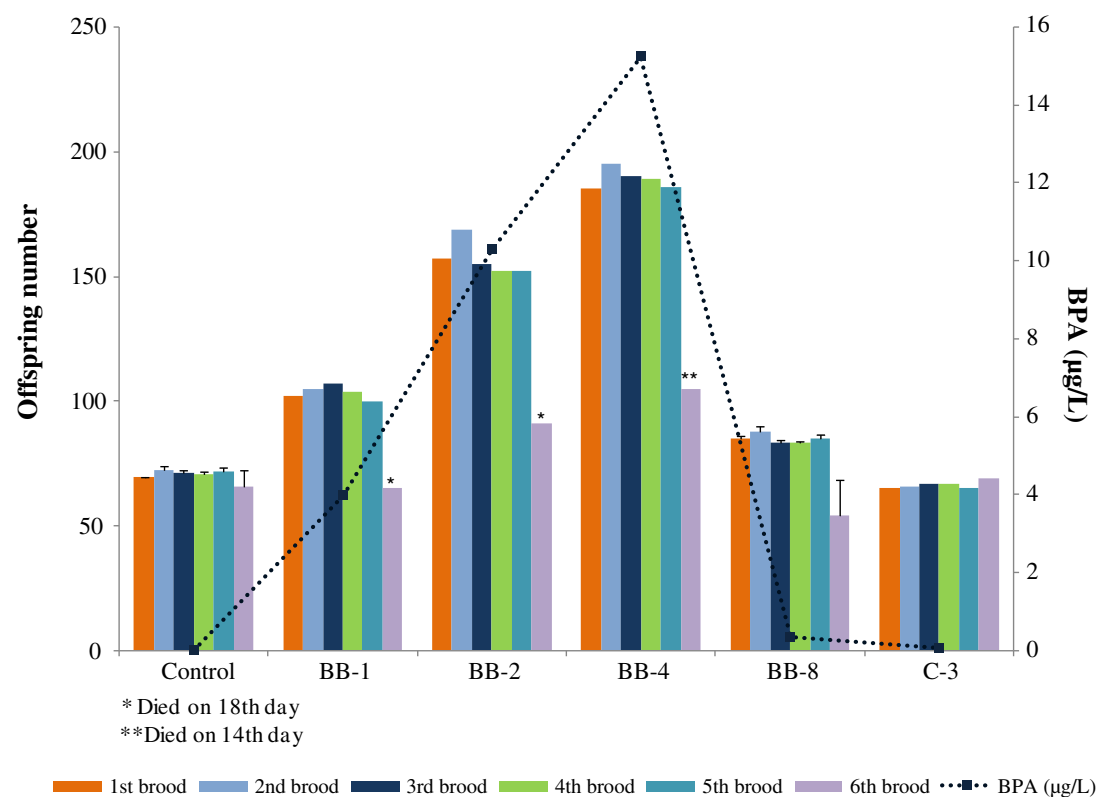

are exposed to mixtures (Kortenkamp et al. 2012; Loureiro et al. 2010; Barata et al. 2006).

\section{Conclusions}

An analytical method for the assessment of BPA migration from plastic containers was validated according to international conventions and allowed the quantification of very low levels of BPA. The migration of BPA from several baby bottles and other plastic containers revealed, in some cases, a significant release of BPA indicating that a broader range of foodstuff may be contaminated with endocrine disruptors when packed in plastics.

Ecotoxicological acute test results were similar to those reported by other authors and the reproduction test showed no significant differences comparing to control, although it was observed a precocious maturity in the concentration of $3,000 \mu \mathrm{g} / \mathrm{L}$. Additionally, single and multigenerational tests were conducted using some containers previously tested concerning BPA migration. Culturing of D. magna in plastic containers filled with defined culturing medium led to a significant increase of its reproductive output (neonates per female) in all PC brands tested ( $145.1 \pm 4.3 \%$ to $264.7 \pm 3.8 \%$ ), both in single as in multigenerational tests, in comparison with the negative control group $(100.3 \pm 1.6 \%)$. In contrast, neonate production by daphnids cultured in PP and non-PC bottles was slightly, but not significantly, enhanced (92.5 \pm $2.0 \%$ to $118.8 \pm 1.8 \%$ ).

Interesting results were obtained as low-dosedependent ecotoxicological effects on D. magna were observed, i.e., in the plastic containers, the BPA migration values were positively correlated with the offspring numbers at concentrations far below 3,000 $\mu \mathrm{g} / \mathrm{L}$ (the NOEC calculated value). The positive correlation results obtained allowed establishing a quantifiable approach and a prediction of the toxicity of a chemical mixture from the results of a single substance as already reported by other authors (Ashauer et al. 2006). The results also illustrated the importance of transgenerational studies, since if the test was discontinued after the first generation, a different conclusion about the toxicity of BPA on the fertility of D. magna would be obtained. A magnification of the adverse effects on mortality and fecundity has been observed, which represents a worrying trend for organisms that are chronically exposed to xenoestrogens for many generations (Brennan et al. 2006).

This study demonstrate that the ecotoxicological effects resulting from the exposure to defined concentrations of a substance could be different from those obtained in more realistic exposure conditions, which can lead to very different values of NOEC and LOEC that have been criticized, in the last years, regarding regulatory aspects (Kortenkamp et al. 2012; Warne and van Dam 2008). Therefore, from a legislative point of view, and according the Final Report of the State of the Art Assessment of Endocrine Disruptors, it is of great importance to have information about the spectrum of EDCs that are present in relevant exposure scenarios, as this information is currently fragmentary, and this lack of information makes it likely that the full extent of risks associated with EDCs might be underestimated (Kortenkamp et al. 2011). Thus, a targeted testing strategy for "low-dose" experiments and the selection of mixtures of compounds to be tested along with BPA, reflecting more realistic scenarios, is necessary and requires further investigation for a more accurate risk assessment. 
Acknowledgments Financial support was obtained from FCT programs, PEst-OE/AGR/UI0211/2011 Strategic Project and PTDC/CVT/ 103081/2008. The authors gratefully acknowledge to Prof. José Manuel Costa from CECA and to Maria de Lurdes Delgado from URSFP/DDI for helping us in the preparation and preservation of algae. Also thank to Prof. Luís M. S. Silva-CIETI, Instituto Superior de Engenharia, Instituto Politécnico do Porto for its help in statistical analysis.

Conflict of interest statement The authors declare that there are no conflicts of interest.

\section{References}

Alexander HC, Dill DC, Smith LW, Guiney PD, Dorn P (1988) Bisphenol A: acute aquatic toxicity. Environ Toxicol Chem 7 (1):19-26

Ashauer R, Boxall ABA, Brown CD (2006) Predicting effects on aquatic organisms from fluctuating or pulsed exposure to pesticides. Environ Toxicol Chem 25(11):1899-1912

ASTM (2004) American Society for Testing Materials. Standard Guide for Conducting Daphnia magna. Life Cycle Toxicity Tests. E1193-97

ASTM (2008) American Society for Testing Materials. Standard practice for conducting toxicity tests with fishes, microinvertebrates and amphibians. In: Annual Book of ASTM Standards; Water and Environmental Technology, vol. 11.04; ASTM E729-96 (2007) American Society for Testing and Materials, Philadelphia, PA

Baird DJ, Soares AMVM, Girling A, Barber I, Bradley M, Callow P (1989) The long-term maintenance of Daphnia magna straus for use in ecotoxicity tests: problems and prospects. In: Lokke $\mathrm{H}$, Tyle H, Bro-Rasmussen F, editor. First European Conference on Ecotoxicology, Lyngby: 144-148

Barata C, Baird DJ, Nogueira AJ, Soares AM, Riva MC (2006) Toxicity of binary mixtures of metals and pyrethroid insecticides to Daphnia magna Straus. Implications for multi-substance risks assessment. Aquat Toxicol 78(1):1-14

Brennan SJ, Brougham CA, Roche JJ, Fogarty AM (2006) Multigenerational effects of four selected environmental oestrogens on Daphnia magna. Chemosphere 64(1):49-55

Canada Environment. Consultation Document: Phenol, 4,4'-(1Methylethylidene)bis-(Bisphenol A) (2009) Chemical Abstracts Service Registry Number 80-05-7

Caspers N (1998) No estrogenic effects of bisphenol A in Daphnia magna STRAUS. Bull Environ Contam Toxicol 61(2):143-148

Cunha SC, Fernandes JO (2010) Quantification of free and total bisphenol $\mathrm{A}$ and bisphenol $\mathrm{B}$ in human urine by dispersive liquid-liquid microextraction (DLLME) and heart-cutting multidimensional gas chromatography-mass spectrometry (MD-GC/MS). Talanta 83 (1):117-125

De Coensel N, David F, Sandra P (2009) Study on the migration of bisphenol-A from baby bottles by stir bar sorptive extractionthermal desorption-capillary GC-MS. J Sep Sci 32(21):38293836

EC, European Commission (2010) European Union Risk Assessment Report, CAS: 80-05-7 EINECS No: 201-245-8. Environment Addendum of April 2008. 4,4'-isopropyldenediphenol (BisphenolA) Part 1 Environment. Joint Research Centre, Institute for Health and Consumer Protection

EC, European Commission (2011) Commission Directive 2011/8/EU of 28 January 2011 amending Directive 2002/72/EC as regards the restriction of use of Bisphenol $\mathrm{A}$ in plastic infant feeding bottles. Off J Eur Union L26:11-14
EFSA, European Food Safety Authority (2012) Food Contact Materials, Bisphenol A, http://www.efsa.europa.eu/en/topics/topic/bisphenol.htm?wtrl=01, accessed May 2012

Ehrlich S, Williams PL, Missmer SA, Berry KF, Petrozza J, Hauser R (2011) Urinary bisphenol A and implantation failure among women undergoing in vitro fertilization. Fertil Steril 96(3):S6-S7

Erler C, Novak J (2010) Bisphenol A exposure: human risk and health policy. J Pediatr Nurs 25(5):400-407

EU, European Union (2003) European Union Risk Assessment Report. 4,4' Isopropylidenediphenol (Bisphenol-A), EINECS No: 201245-8. Final Report, United Kingdom

González-Castro MI, Olea-Serrano MF, Rivas-Velusco AM, Medina-Rivero E, Ordoñez-Acevedo LG, De Léon-Rodriguez A (2011) Phthalates and bisphenols. Migration in Mexican food cans and plastic food containers. Bull Environ Contam Toxicol 86:627-631

Guart A, Bono-Blay F, Borrell A, Lacorte S (2011) Migration of plasticizers phthalates, bisphenol A and alkylphenols from plastic containers and evaluation of risk. Food Addit Contam Part A Chem Anal Control Expo Risk Assess 28(5):676-685

EURACHEM Guide (1998) The fitness for purpose of analytical methods. Laboratory guide to method validation and related topics. Teddington, United Kingdom

ICH, International Conference on Harmonisation (1994) Validation of analytical methods definitions and terminology, Q2A Guideline

ICH, International Conference on Harmonisation (1995) Validation of analytical procedures: definitions and terminology $(\mathrm{CPMP} / \mathrm{ICH} /$ 381/95) Q2A and Methodology (CPMP/ICH/281/95) Q2B

ICH, International Conference on Harmonisation (2005) Harmonised tripartite guideline. Validation of analytical procedures: text and methodology Q2(R1)

ISO, International Organization for Standardization 6341 (2010) Water quality-determination of the inhibition of the mobility of Daphnia magna Straus (Cladocera, Crustacea) - acute toxicity test

Kortenkamp A, Martin O, Faust M, Evans R, McKinlay R, Orton F, Rosivatz E (2011) State of the art assessment of endocrine disrupters. Final Report. Project Contract Number 070307/2009/ 550687/SER/D3

Kortenkamp A, Evans R, Martin O, McKinlay R, Orton F, Rosivatz E (2012) State of the art assessment of endocrine disrupters. Final Report. Project Contract Number 070307/2009/550687/SER/D3 Annex 1, Summary of the state of the science. Revision version of the draft published in June 2011 by the European Commission, DG Environment

Kubwabo C, Kosarac I, Stewart B, Gauthier BR, Lalonde K, Lalonde PJ (2009) Migration of bisphenol A from plastic baby bottles, baby bottle liners and reusable polycarbonate drinking bottles. Food Addit Contam 26(6):928-937

Loureiro S, Svendsen C, Ferreira AL, Pinheiro C, Ribeiro F, Soares AM (2010) Toxicity of three binary mixtures to Daphnia magna: comparing chemical modes of action and deviations from conceptual models. Environ Toxicol Chem 29(8):1716-1726

Maia J, Cruz JM, Sendon R, Bustos J, Sanchez JJ, Paseiro P (2009) Effect of detergents in the release of bisphenol A from polycarbonate baby bottles. Food Res Int 42(10):1410-1414

Mansilha C, Melo A, Rebelo H, Ferreira IMPLVO, Pinho O, Domingues V, Pinho C, Gameiro P (2010) Quantification of endocrine disruptors and pesticides in water by gas chromatography-tandem mass spectrometry. Method validation using weighted linear regression schemes. J Chromatogr A 1217:6681-6691

Mansilha C, Rocha S, Gameiro P, Pinho C, Ferreira IMPLVO, Silva P, Domingues V (2012) Interlaboratory validation of an environmental monitoring method for trace analysis of endocrine disrupting compounds. Anal Methods. doi:10.1039/C2AY25450F 
Meeker JD, Ehrlich S, Toth TL, Wright DL, Calafat AM, Ye X, Trisini AT, Hauser R (2010) Semen quality and sperm DNA damage in relation to urinary bisphenol A among men from an infertility clinic. Reprod Toxicol 30(4):532-539

Miller JN, Miller JC (2005) Statistics and chemometrics for analytical chemistry, 5th edn. Pearson Education Limited, England

Mu X, Rider CV, Hwang GS, Hoy H, LeBlanc GA (2005) Covert signal disruption: anti-ecdysteroidal activity of bisphenol-A involves cross talk between signaling pathways. Environ Toxicol Chem 24(1):146-152

Nam SH, Seo YM, Kim MG (2010) Bisphenol A migration from polycarbonate baby bottle with repeated use. Chemosphere 79 (9):949-952

National Research Council (2008) Phthalates and cumulative risk assessment: the task ahead. National Academies Press, Washington

NCCLS, National Committee for Clinical Laboratory Standards (2002) Approved Guideline, C43-A. Gas Chromatography/Mass Spectrometry (GC/MS) Confirmation of Drugs

NCCLS, National Committee for Clinical Laboratory Standards (2004) Approved guideline, EP17-A. Protocols for Determination of Limits of Detection and Limits of Quantitation

Regulation (EC) No 1107/2009 of the European Parliament and of the Council of 21 October 2009, concerning the placing of plant protection products on the market and repealing Council Directives 79/117/EEC and 91/414/EEC

Regulation (EC) No 1907/2006 of the European Parliament and of the Council of 18 December 2006, concerning the Registration, Evaluation, Authorisation and Restriction of Chemicals (REACH), establishing a European Chemicals Agency, amending Directive 1999/45/EC and repealing Council Regulation (EEC) No 793/93 and Commission Regulation (EC) No 1488/94 as well as Council Directive 76/769/EEC and Commission Directives 91/ 155/EEC, 93/67/EEC, 93/105/EC and 2000/21/EC

OECD, Organisation for Economic Co-operation and Development (1984) Daphnia sp., acute immobilisation test and reproduction test. In: Part I-the $24 \mathrm{~h}$ EC 50 Acute Immobilisation Test

OECD, Organisation for Economic Co-operation and Development (2004) Guidelines for testing of chemicals. Test No. 202: Daphnia sp. Acute Immobilisation Test

OECD, Organisation for Economic Co-operation and Development (2011) Conceptual framework for the testing and assessment of endocrine disrupting chemicals http://www.oecd.org/document/58/0,3343, en 2649343772348794 1_1_1_1,00.html, Assessed December 2011

OECD, Organisation for Economic Co-operation and Development (2012) Guidelines for testing of chemicals. Test No. 211: Daphnia magna Reproduction Test
Oetken M, Bachmann J, Schulte-Oehlmann U, Oehlmann J (2004) Evidence for endocrine disruption in invertebrates. Int Rev Cytol 236:1-44

SANCO (2009) Method validation and quality control procedures for pesticide residues analysis in food and feed. European Commission. SANCO/10684/2009 (01/01/2010)

SEC (2011) European Commission Report 1001 final. 4th Report on the implementation of the "Community Strategy for Endocrine Disrupters" a range of substances suspected of interfering with the hormone systems of humans and wildlife (COM (1999) 706)

Staples CA, Dome PB, Klecka GM, Oblock ST, Harris LR (1998) A review of the environmental fate, effects, and exposures of bisphenol A. Chemosphere 36(10):2149-2173

Stottmeister E, Heemken OP, Hendel P, Donnevert G, Frey S, Allmendinger H, Sawal G, Jandel B, Geiss S, Donau R, Koch A, Heinz I, Ottaviani M, Veschetti E, Hartl W, Kubwabo C, Benthe C, Tobinski V, Woldmann H, Spilker R (2009) Interlaboratory trial on the analysis of alkylphenols, alkylphenol ethoxylates, and bisphenol $\mathrm{A}$ in water samples according to ISO/CD 18857-2. Anal Chem 81 (16):6765-6773

USEPA, U.S. Environmental Protection Agency (2002) Methods for measuring the acute toxicity of effluents and receiving waters to freshwater and marine organisms. EPA-821-R-02-012

USEPA, U.S. Environmental Protection Agency (2003) Framework for cumulative risk assessment. U.S. EPA/ORD/NCEA, Washington, DC. EPA/600/P-02/001F

USEPA, U.S. Environmental Protection Agency (2010) Bisphenol A action plan. CASRN 80-05-7

USFDA, U.S. Food and Drug Administration (2001) Guidance for industry-bioanalytical method validation. U.S. Department of Health and Human Services

USFDA, U.S. Food and Drug Administration (2007) Guidance for industry: preparation of pre-market submissions for food contact substances: chemistry recommendations

USFDA, U.S. Food and Drug Administration (2012) Update on Bisphenol A for use in food contact applications

Viñas P, Campillo N, Martínez-Castillo N, Hernández-Córdoba M (2010) Comparison of two derivatization-based methods for solid-phase microextraction-gas chromatography-mass spectrometric determination of bisphenol $\mathrm{A}$, bisphenol $\mathrm{S}$ and biphenol migrated from food cans. Anal Bioanal Chem 397 (1):115-125

Wagner M, Oehlmann J (2009) Endocrine disruptors in bottled mineral water: total estrogenic burden and migration from plastic bottles. Environ Sci Pollut Res 16(3):278-286

Warne MJ, van Dam R (2008) NOEC and LOEC data should no longer be generated or used. Australas J Ecotoxicol 14:1-5 